\title{
PSPC1 is a new contextual determinant of aberrant subcellular translocation of oncogenes in tumor progression
}

\author{
Yaw-Dong Lang and Yuh-Shan Jou* ${ }^{*}$
}

\begin{abstract}
Dysregulation of nucleocytoplasmic shuttling is commonly observed in cancers and emerging as a cancer hallmark for the development of anticancer therapeutic strategies. Despite its severe adverse effects, selinexor, a selective firstin-class inhibitor of the common nuclear export receptor XPO1, was developed to target nucleocytoplasmic protein shuttling and received accelerated FDA approval in 2019 in combination with dexamethasone as a fifth-line therapeutic option for adults with relapsed refractory multiple myeloma (RRMM). To explore innovative targets in nucleocytoplasmic shuttling, we propose that the aberrant contextual determinants of nucleocytoplasmic shuttling, such as PSPC1 (Paraspeckle component 1), TGIF1 (TGF- $\beta$ Induced Factor Homeobox 1), NPM1 (Nucleophosmin), Mortalin and EBP50, that modulate shuttling (or cargo) proteins with opposite tumorigenic functions in different subcellular locations could be theranostic targets for developing anticancer strategies. For instance, PSPC1 was recently shown to be the contextual determinant of the TGF- $\beta$ prometastatic switch and PTK6/ $\beta$-catenin reciprocal oncogenic nucleocytoplasmic shuttling during hepatocellular carcinoma (HCC) progression. The innovative nucleocytoplasmic shuttling inhibitor PSPC1 C-terminal 131 polypeptide (PSPC1-CT131), which was developed to target both the shuttling determinant PSPC1 and the shuttling protein PTK6, maintained their tumor-suppressive characteristics and exhibited synergistic effects on tumor suppression in HCC cells and mouse models. In summary, targeting the contextual determinants of nucleocytoplasmic shuttling with cargo proteins having opposite tumorigenic functions in different subcellular locations could be an innovative strategy for developing new therapeutic biomarkers and agents to improve cancer therapy.
\end{abstract}

Keywords: PSPC1, Nucleocytoplasmic shuttling, Oncogenic switch, Selective inhibitor of nucleocytoplasmic shuttling, TGIF1, NPM, Mortalin and EBP50

\section{Introduction}

Nucleocytoplasmic shuttling is the dynamic physiological movement of macromolecules, including proteins and RNAs, into the proper cellular compartments for performing their designated biological functions and maintaining cellular homeostasis [1]. Although nucleocytoplasmic protein shuttling has been observed for decades, the detailed molecular mechanisms and

*Correspondence: jou@ibms.sinica.edu.tw

Institute of Biomedical Sciences, Academia Sinica, 11529 Taipei, Taiwan their translational applications have only recently been explored. Indeed, the protein transportation process is complex and tightly coordinated in both directions across the nuclear envelope, and it includes sequential protein interaction steps to (a) recognize the protein import or export signal by an import or export receptor, (b) dock the transporting protein with the import/export receptor to nuclear pore complexes (NPCs), (c) translocate the shuttling protein across the nuclear pore, $(d)$ release the transported protein, and then (e) recycle the transport original author(s) and the source, provide a link to the Creative Commons licence, and indicate if changes were made. The images or other third party material in this article are included in the article's Creative Commons licence, unless indicated otherwise in a credit line to the material. If material is not included in the article's Creative Commons licence and your intended use is not permitted by statutory regulation or exceeds the permitted use, you will need to obtain permission directly from the copyright holder. To view a copy of this licence, visit http://creativecommons.org/licenses/by/4.0/. The Creative Commons Public Domain Dedication waiver (http://creativeco mmons.org/publicdomain/zero/1.0/) applies to the data made available in this article, unless otherwise stated in a credit line to the data. 
factors in the shuttling machinery to facilitate protein shuttling [2].

In eukaryotic cells, the contextual determinant of nucleocytoplasmic shuttling is not only responsible for propagating signaling by transducing internal and external stimuli such as signals from growth factors (e.g., TGF- $\beta$ ), cytokines (e.g., IL-6), or even stresses to activate signal transducers such as Smads, $\beta$-catenin, ERKs, STAT3, p53, and NF-kB by posttranslational modification, but also these factors then enter the nucleus to interact with spatiotemporal cofactors in the designated cellular environment for activation of downstream signaling and responses with proper cellular functions [3]. Generally, canonical shuttling proteins contain a nuclear localization signal (NLS) domain for importin-mediated protein import into the nucleus or a nuclear export signal (NES) domain for the nuclear export receptor CRM1 (chromosome region maintenance 1, also called exportin 1, XPO1) for export into the cytoplasm [4]. A well-studied example is that DNA damage can induce the phosphorylation of the cytoplasmic tumor suppressor protein p53 by kinases, including ataxia telangiectasia mutated (ATM) and ATM-Rad3-related (ATR), followed by interaction of the p53 NLS-like domain with importins to dock on NPCs for nuclear import [5]. After p53 acetylation by $\mathrm{p} 300 / \mathrm{CREB}$-binding protein (CBP) to enhance the p53 DNA-binding affinity, p53 accumulated in the nucleus in response to DNA damage can mediate cell cycle arrest, apoptosis and senescence [6]. Then, ubiquitylation $(\mathrm{Ub})$ of p53 mediated by murine double minute 2 (MDM2), an E3 ligase, transports p53 via its NES-like motif to CRM1, leading to the export of nuclear p53 into the cytoplasm for ubiquitin-dependent proteasomal degradation. The elegant and dynamic modulation of p53 nucleocytoplasmic shuttling via the MDM2 interaction helps to maintain a low level of p53 in normal cells and to deal with damage-induced stress by increasing the p53 level to maintain cell homeostasis.

Dynamic nucleocytoplasmic shuttling is a crucial mechanism to keep proteins in the appropriate subcellular localization and to allow them to perform proper functions in a given physiological context. Therefore, aberrancies in the proteins involved in nucleocytoplasmic protein shuttling can lead to incorrect subcellular localization of proteins associated with human diseases. Some review articles have provided a comprehensive summary of potential aberrancies in the protein trafficking machinery, including mutations and/or aberrant expression of protein shuttling signals, transporters in the shuttling machinery, and posttranslational modifications of cargo and signal transducers causing alterations in protein interaction networks and aggregation of misfolded proteins leading to mislocalization of cargo proteins associated with human diseases such as cancer, neurodegenerative diseases, osteoporosis and anemia [4, $7,8]$.

With the body of information on the mechanisms of nucleocytoplasmic shuttling generated over the past few decades, aberrant subcellular localization of oncogenes and tumor suppressor genes has been found to occur frequently in cancers and promote tumorigenesis, metastasis and drug resistance in divergent cancer types $[9,10]$. Therefore, aberrant nucleocytoplasmic shuttling of proteins and RNAs has emerged as a hallmark of cancer with great potential to serve as a theranostic target for cancer therapy. Indeed, it has been reported that XPO1 exports at least $221 \mathrm{NES}$-containing proteins plus a subset of nuclear RNAs from the nucleus to the cytoplasm. Selective inhibitors of nuclear transport (SINEs) are novel inhibitors of XPO1 that target the protein-interacting residue Cys528 in the NES-binding pocket of XPO1 as orally bioavailable inhibitors including KPT-185, KPT251, KPT-276, selinexor, eltanexor and verdinexor [1115]. Selinexor, a first-in-class nuclear export inhibitor targeting canonical nucleocytoplasmic shuttling, causes the accumulation of tumor suppressor proteins accompanied by a reduction in oncoproteins. Selinexor was approved by U.S. Food and Drug Administration (FDA) in 2019 in combination with dexamethasone as a fifthline therapeutic option for adult patients with relapsed refractory multiple myeloma (RRMM) [16]. However, the use of SINEs in cancer therapy remains challenging because of their low therapeutic efficacy against solid tumors in phase I and II clinical trials and their severe adverse effects of low platelet counts and low blood sodium levels that lead to thrombocytopenia, neutropenia, fatigue, and nausea [17].

Owing to advances in the molecular pathological mechanisms of diseases, different nucleocytoplasmic shuttling (or cargo) proteins have been uncovered, including categories of transcription factors/cofactors (e.g., STAT3, p53, etc.; reviewed in [18, 19]), RNA-binding proteins (e.g., HuR and hnRNPs; reviewed in [20]), hormone and growth factor receptors (e.g., the androgen receptor and EGFR; reviewed in $[21,22])$, translation initiation factors (e.g., eIF4E; reviewed in [23]) and kinases (e.g., proteintyrosine kinase 6, PTK6; also called breast tumor kinase, Brk) [24]. Instead of relying on conventional NLS- and NES-like domains, many of the cargo proteins have been shown to dynamically shuttle between the nucleus and cytoplasm in NLS and NES domain-independent manners (e.g., $\beta$-catenin) via interaction with other chaperone or interacting proteins with unknown mechanisms $[24,25]$. During both canonical and noncanonical 
nucleocytoplasmic shuttling, cargo proteins interact with and are sequestered by the "contextual determinants" of nucleocytoplasmic shuttling in a specific subcellular localization in a cell context-dependent manner to perform their designated pathophysiological function. The strategy of developing innovative inhibitors by targeting the contextual determinants of nucleocytoplasmic shuttling might confer some advantages over the conventional design of SINEs targeting common machinery proteins, such as XPO1, in nucleocytoplasmic shuttling. First, contextual determinants of nucleocytoplasmic shuttling are commonly induced under aberrant stresses (e.g., somatic mutations) in a cell content-dependent manner to trigger pathological events. Second, selective targeting of both interacting contextual determinants and cargo proteins might maintain their tumor-suppressive activities and exhibit synergistic tumor-suppressive effects. Finally, specific targeting of a selected contextual determinant of aberrant nucleocytoplasmic shuttling might result in low toxicity to cancer patients, based on clinical experience with targeted therapies in cancers.

PSPC1 (paraspeckle component 1) was recently identified as a contextual determinant of tumor progression in multiple cancer types involving oncogenic reprogramming to switch proapoptotic TGF- $\beta$ to prometastatic TGF- $\beta$ via hijacking of $\operatorname{Smad} 2 / 3$ targeting [26].
Moreover, PSPC1, as a substrate of nuclear PTK6, is the contextual determinant of PTK6 nucleocytoplasmic shuttling and modulates the switch of tumor-suppressive PTK6 in the nucleus of normal or premalignant cells to oncogenic PTK6 in the cytoplasm of malignant cancer cells [27]. An innovative dual inhibitor derived from a unique C-terminal polypeptide composed of 131 amino acids of PSPC1 targeting both oncogenic PSPC1 and PTK6 nucleocytoplasmic shuttling was shown to exhibit synergistic tumor-suppressive effects in HCC cell lines and mouse models [28]. These observations elucidated that agents targeting aberrant oncogenic contextual determinants and nucleocytoplasmic shuttling proteins might be a new class of anticancer theranostic targets with the anticancer feature of tissue specificity for reducing cytotoxicity and producing synergistic effects on tumor suppression via combined targeting of shuttling determinant and cargo proteins.

In this review article, we discuss 5 aberrant contextual determinants of nucleocytoplasmic shuttling-PSPC1, TGIF1, NPM, Mortalin and EBP50-meeting these criteria and note their detailed mechanisms of action as oncogenic nucleocytoplasmic shuttling switches, potential use as biomarkers for stratification of cancer patients, and possibilities as putative therapeutic agents to potentially improve cancer therapy (Fig. 1; Table 1).

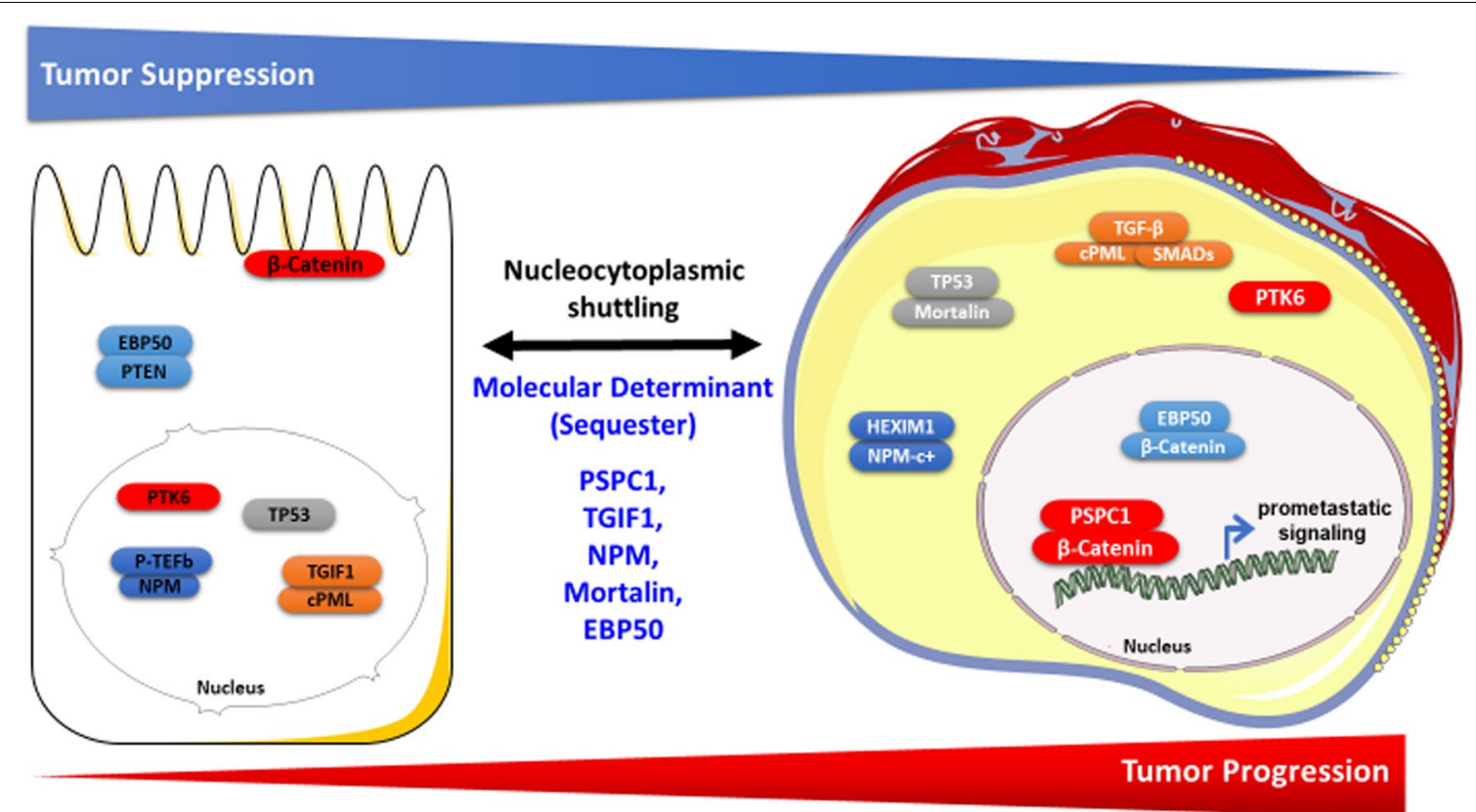

Fig. 1 Phenotypic characteristics and contextual determinants of nucleocytoplasmic shuttling in tumor progression. Schematic representation of subcellular localizations of the contextual determinants and nucleocytoplasmic shuttling proteins involved in tumor progression. The left side of the figure shows normal or benign cells with low tumorigenic potential. The right side of the figure shows malignant cancer cells. The contextual determinant and the nucleocytoplasmic shuttling protein involved in the same subcellular translocation event are highlighted in the same color 


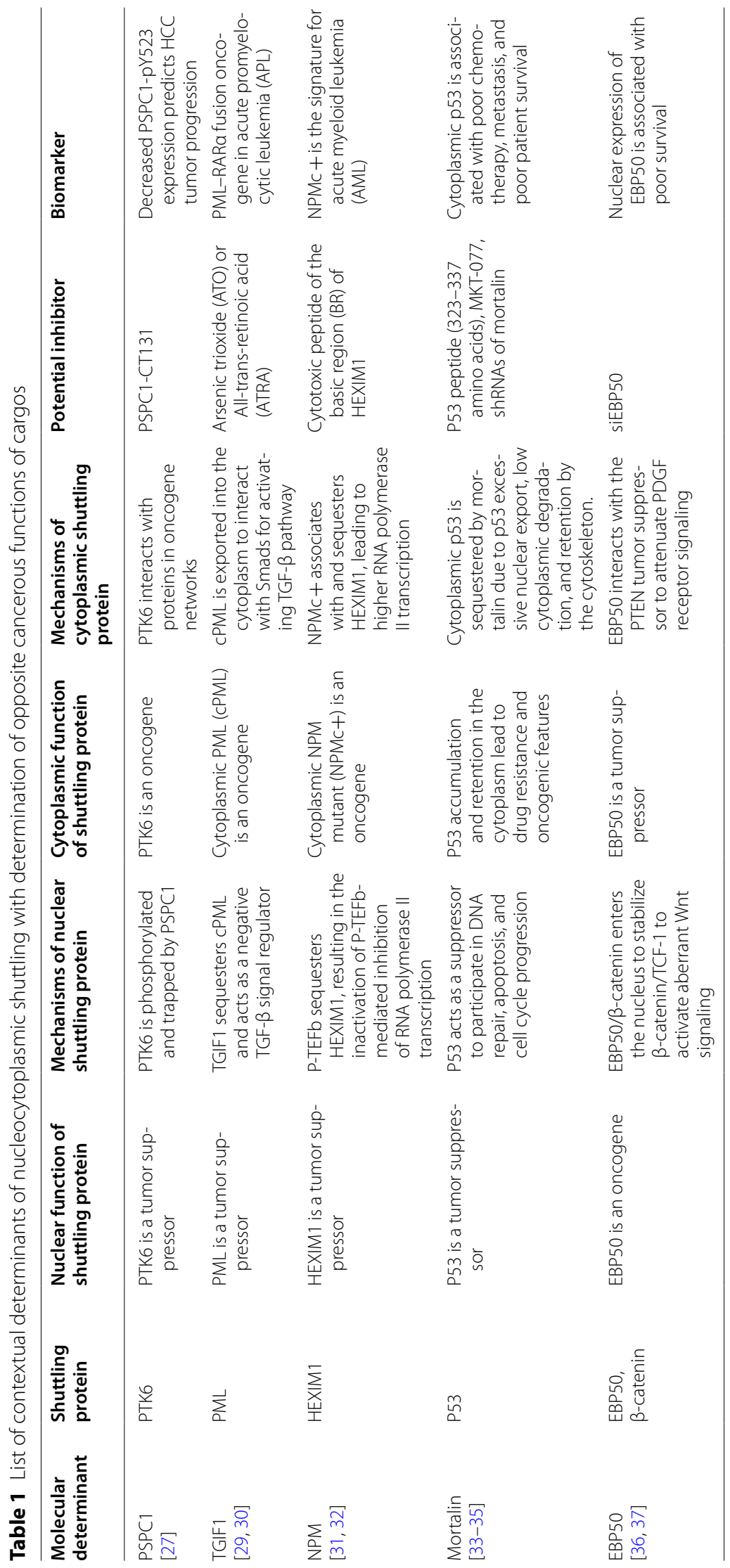




\section{PSPC1 is the contextual determinant of the reciprocal nucleocytoplasmic shuttling of oncogenic PTK6 and $\beta$-catenin}

PSPC1 (Paraspeckle component 1) is a nuclear protein located at punctate subnuclear structures neighboring splicing speckles, called paraspeckles, that are mainly composed of three Drosophila behavior/human splicing (DBHS) proteins-PSPC1; splicing factor proline- and glutamine-rich (SFPQ), also called PSF; and non-POUdomain-containing octamer-binding protein (NONO), also called p54nrb-and a long noncoding RNA called NEAT1 (Nuclear enriched abundant transcript 1) [38]. PSPC1 is a putative transcription factor/cofactor and is known as an androgen receptor coactivator in differentiating Sertoli cell nuclei [39], participates in the DNA damage response [40], recruits TET2 to ERVL-associated genes for their transcriptional repression via histone deacetylases and posttranscriptional destabilization of RNAs through $5 \mathrm{hmC}$ modification [41], promotes the differentiation-dependent nuclear export of adipocyte RNAs [42], potentiates IGF1R expression and augments cell motility [43], and acts as a contextual master driver of prometastatic reprogramming of transforming growth factor $\beta 1$ (TGF- $\beta 1$ ) signaling toward a prometastatic phenotype associated with activating epithelial-to-mesenchymal transition (EMT), stemness and tumor metastasis in multiple cancer types $[26,44]$.

To better understand the roles of PSPC1 in tumor progression and develop therapeutic strategies to halt tumor metastasis, we also conducted integrated proteomics and transcriptomic analyses and found that PSPC1 is a contextual determinant of tumor progression to potentiate the reciprocal oncogenic switches of cytoplasmic protein-tyrosine kinase 6 (PTK6) and nuclear $\beta$-catenin subcellular translocation to augment Wnt3a autocrine signaling in tumor progression [27]. PTK6 (or Brk) belongs to the nonreceptor tyrosine kinase FRK/PTK6 family and is composed of Src homology 3 (SH3), Src homology 2 (SH2) and kinase (SH1) domains; it is known to be upregulated in multiple cancer types and normal epithelial cells [45]. It is well noted that PTK6 acts as a tumor suppressor localized in the nucleus through phosphorylation of some RNA-binding proteins, such as Sam68 and the splicing factor PSF, to promote the cytoplasmic relocalization of RNA-binding proteins and to impair their binding to polypyrimidine RNAs, leading to cell cycle arrest [24]. In differentiated prostate cancer cells, nuclear localization of PTK6 may provide a weak tumorigenic indicator for prostate tumor progression [46]. In contrast, PTK6 has been shown to be overexpressed in multiple cancer types as an oncogene and to be localized in the cytoplasm and at the cell membrane [47]. Cytoplasmic PTK6 can interact with over 30 identified substrates within the cytosol and participate in facilitating oncogenic functions of cancer cells to enhance their migration and invasion $[47,48]$. PSPC1 is the first protein substrate to be identified as a contextual determinant of PTK6 subcellular localization accompanied by a switch in the oncogenic function of PTK6.

PTK6 was identified via its interaction with PSPC1 in the nucleus by proteomic analysis and acts as a tumor suppressor to abrogate the oncogenic effects of PSPC1. Indeed, in premalignant cancer cells with low PSPC1 expression, PTK6 is sequestered by its tyrosine-phosphorylated substrate and interacts with PSPC1-phospho-Y523 in the nucleus to suppress the tumorigenic functions of PSPC1. A newly induced antibody against Y523-phosphorylated PSPC1 was applied in immunohistochemical (IHC) experiments on human HCC tissues, which demonstrated that lower expression of Y523-phosphorylated PSPC1 was associated with poor survival in HCC patients. Diminished expression of Y523-phosphorylated PSPC1 indicated loss of PTK6 sequestration in the nucleus and shuttling to the cytoplasm and cell membrane to activate oncogenic PTK6. However, in cells of advanced HCC with high PSPC1 expression, PTK6 can translocate to the cytoplasm and cell membrane as an oncogene, and reciprocally, cytoplasmic $\beta$-catenin can translocate to the nucleus to interact with PSPC1 to facilitate synergistic oncogenic effects such as EMT, Wnt3a autocrine signaling and stemness toward metastasis. Therefore, PSPC1 is the contextual determinant for the reciprocal oncogenic subcellular translocation of cytoplasmic PTK6 and nuclear $\beta$-catenin to exert synergistic effects on oncogenic tumor progression (Fig. 2) [27]. We found that PSPC1 overexpression can also be a contextual activator to stimulate the nuclear translocation of $\beta$-catenin with enhanced interaction of PSPC1 and $\beta$-catenin in the nucleus and to upregulate Wnt3a autocrine signaling to potentiate synergistic oncogenic progression mediated by PSPC1 and PTK6 in HCC cells. Moreover, targeting the PSPC1/PTK6 interaction with PSPC1 C-terminal 131 polypeptide (PSPC1-CT131) as an innovative therapeutic agent in HCC cells was found to reverse the nucleocytoplasmic shuttling of PTK6 and $\beta$-catenin, suppress the expression of the autocrine oncogenic growth factors Wnt3a and TGF- $\beta$, and inhibit tumor progression and metastasis in vivo in HCC mouse models.

\section{TGIF1 is the contextual determinant of PML nucleocytoplasmic shuttling}

TGF- $\beta$ Induced Factor Homeobox 1 (TGIF1) is known to function as a nuclear corepressor of TGF- $\beta$ signaling through multiple mechanisms, such as recruiting Smad2/4 and histone deacetylases (HDACs) to form a 


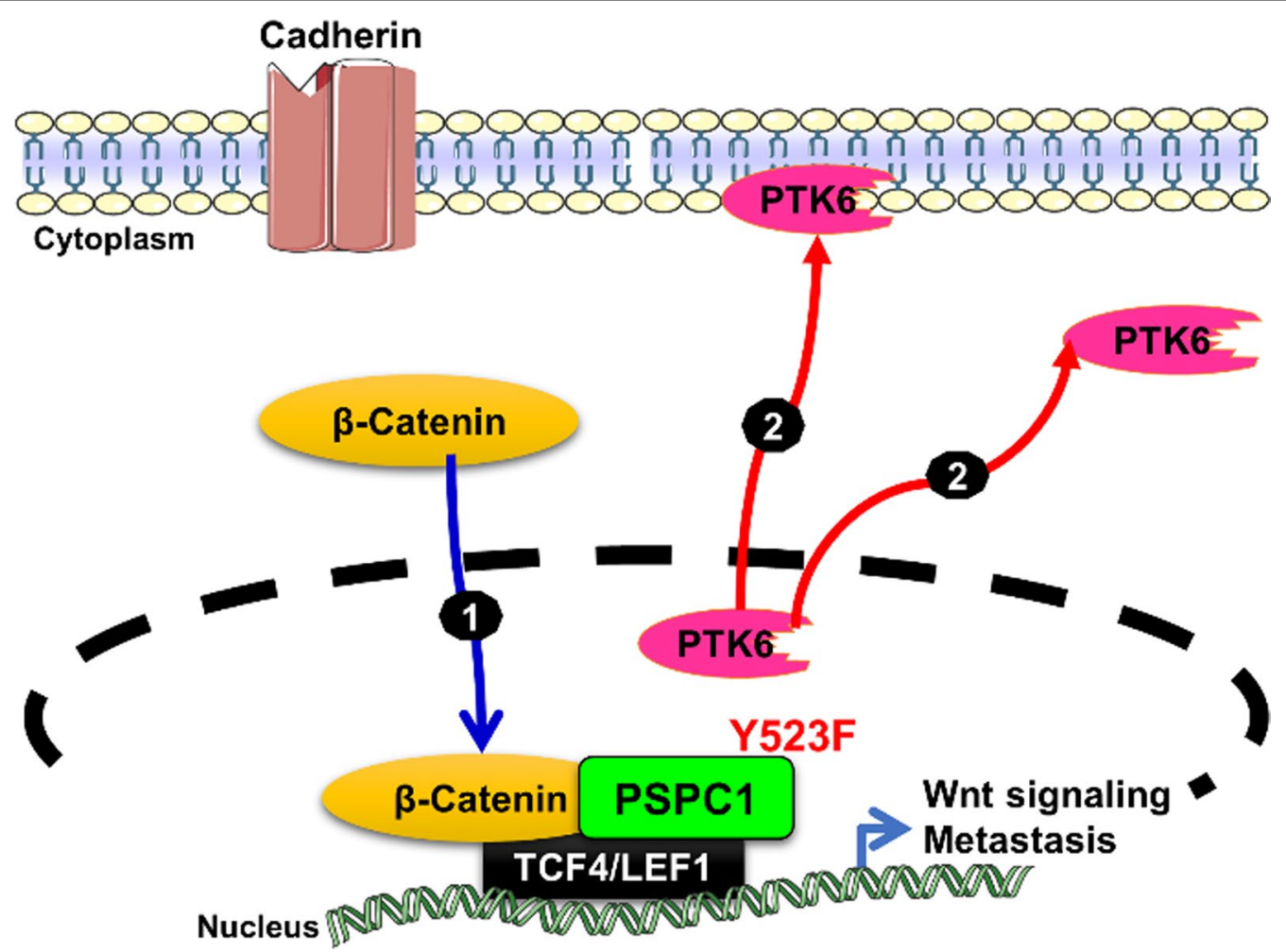

Fig. 2 PSPC1 is the contextual determinant of PTK6/ $\beta$-catenin reciprocal nucleocytoplasmic shuttling. (1) In cells of advanced cancer with high PSPC1 expression, PSPC1 upregulation or mutation of amino acid residue 523 in PSPC1 from tyrosine to phenylalanine (PSPC1-Y523F) can determine oncogenic subcellular translocation to exert synergistic effects on the translocation of cytoplasmic $\beta$-catenin to the nucleus and preferentially interact with PSPC1 to facilitate synergistic oncogenic effects (2) PTK6 can translocate to the cytoplasm and cell membrane as an oncogene to facilitate synergistic oncogenic effects such as epithelial-to-mesenchymal transition (EMT), Wnt3a autocrine signaling and stemness promoting metastasis

transcriptional repressor complex on the Smad target promoter to repress the transcription of TGF- $\beta$ signaling [49], interacting with the E3 ubiquitin ligase Tiul1 (TGIFinteracting ubiquitin ligase 1, or WWP1, WW Domain Containing E3 Ubiquitin Protein Ligase 1) to degrade Smad2 via ubiquitin-dependent proteasomal degradation [50], and sequestering cytoplasmic promyelocytic leukemia (cPML) in the nucleus to prevent its shuttling to the cytoplasm to interact with Smad2/3 and TGF- $\beta$ receptors (T $\beta R I$ and T $\beta$ RII) to activate oncogenic TGF- $\beta$ signaling in cancer cells [29, 30, 51] (Fig. 3).

Promyelocytic leukemia protein (PML) was originally found in patients with a rare subtype of acute myeloid leukemia (AML) called acute promyelocytic leukemia (APL), which expresses a PML-RAR $\alpha$ fusion oncoprotein encoded by $P M L$ and the retinoic acid receptor alpha (RAR $\alpha$ ) chromosomal translocation between chromosomes 15 and 17, t(15;17) [52-55]. In normal cells, nuclear PML forms nuclear multiprotein complexes called PML nuclear bodies (NBs) and functions as a tumor suppressor to modulate the transcription of $\mathrm{p} 53$ and $\mathrm{Rb}$, leading to modulation of apoptosis, cell proliferation, and cell senescence [56]. However, some PML isoforms derived from alternative splicing of mRNAs without nuclear localization signal (NLS) motifs, called cytoplasmic PML (cPML) isoforms, were identified in the cytoplasm and demonstrated to activate TGF- $\beta$ signaling mediating tumor suppression, apoptosis and senescence in a physiological context [29]. On the other hand, cPML was also shown to interact with XPO1 and to be exported from the nucleus to the cytoplasm to promote association with the Smad2/3-dependent canonical TGF- $\beta$ signaling pathway to enhance EMT and invasion of prostate cancer cells [30] (Fig. 3). Clinically, treatment of APL patients and other cancer cells with arsenic trioxide (ATO) and/ or all-trans-retinoic acid (ATRA) was shown to cause proteasomal degradation of PML-RAR $\alpha$ and $\mathrm{cPML}$ to prevent their nucleocytoplasmic shuttling and reverse their tumorigenic effects [57-59]. 


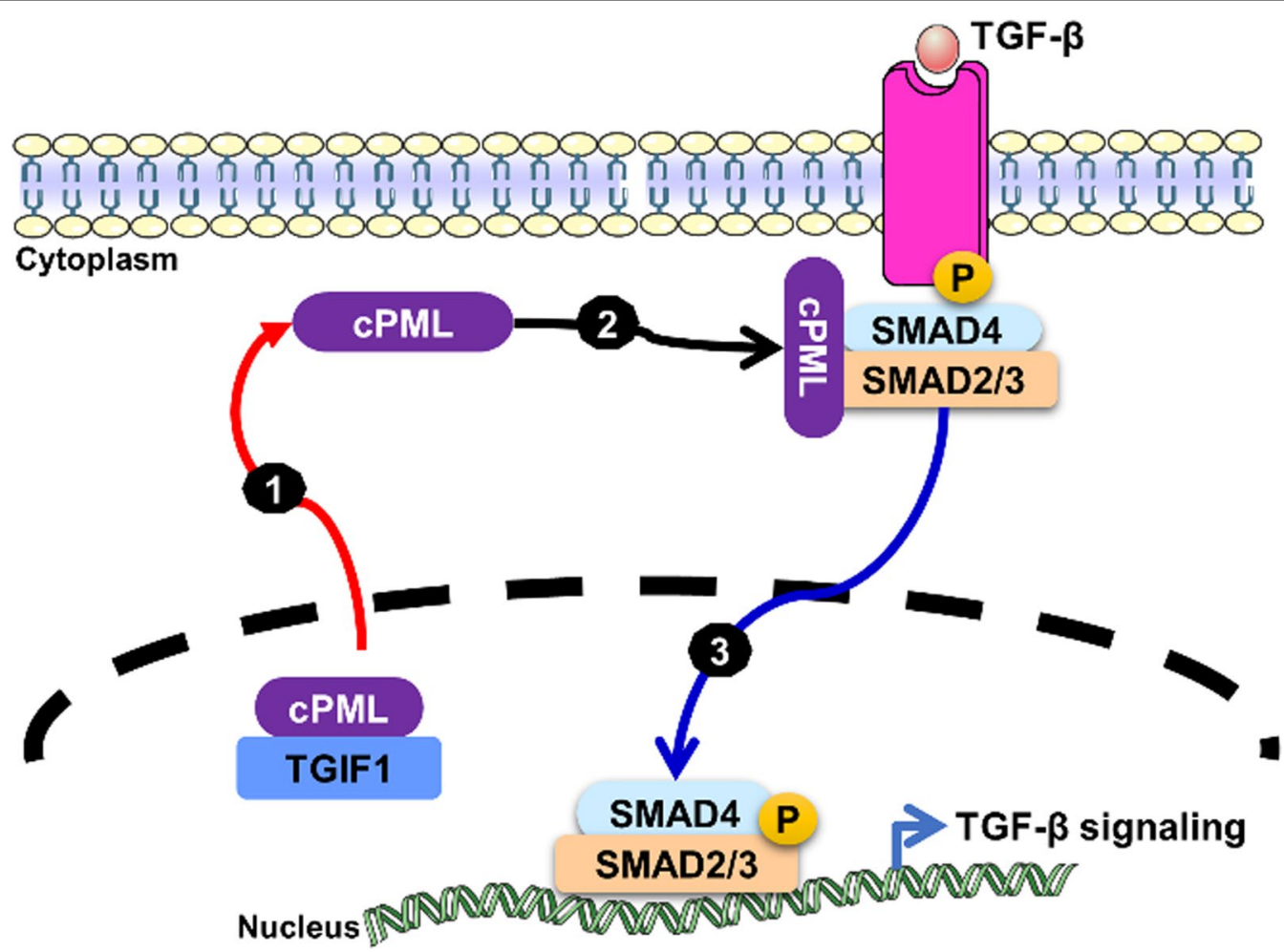

Fig. 3 TGIF1 is the contextual determinant of PML nucleocytoplasmic shuttling. (1) PML delocalization was initiated by escape of nuclear interaction with TGF- $\beta$ Induced Factor Homeobox 1 (TGIF1) to prevent CPML translocation to the cytoplasm. (2) Cytoplasmic promyelocytic leukemia (CPML) appears to preferentially interact with phosphorylated Smad2/3 and acts as an essential activator of TGF- $\beta$ signaling (3) Activation of the canonical TGF- $\beta$ signaling pathway

\section{NPM1 is the contextual determinant of NPM1 and HEXIM1 nucleocytoplasmic shuttling}

NPM1, encoded a protein called nucleophosmin or nucleolar phosphoprotein B23, is associated with nucleolar ribosome biogenesis, nucleolar protein transportation, formation of G-quadruplex nucleic acids, modulation of histone chaperone and chromatin remodeling, and promotion of cell proliferation via the Myc-ARF-p53 axis and SUMOylation [60]. NPM1 is a nucleolar nucleocytoplasmic shuttling protein that has been shown to interact with different protein partners in response to different cellular functions and even redox stress. Overexpressed NPM1 can translocate to the nucleolus via nucleocytoplasmic shuttling to sequester HDM2 and disrupt the p53-HDM2 interaction to promote DNA damage and viral stress-induced activation of p53 [61]. Additionally, NPM1 nucleolar translocation is crucial for c-Myc nucleolar localization and c-Myc-mediated transcription to regulate rRNA synthesis to induce fibroblast proliferation and transformation [62].

NPM1 is commonly upregulated, mutated and chromosomally translocated in hematopoietic cancers and solid tumors [63]. In acute myelogenous leukemia
(AML), NPM mutants are commonly shown to lack a folded C-terminal domain (NPM1c+) and are expressed in the cytoplasm in association with AML development in patients [64]. Therefore, NPM1c + mutations serve as a biomarker for first-line screening in AML patients with myeloid neoplasms defined by the WHO classification. Interestingly, it has been shown that NPM1c + can drive TGF- $\beta /$ Smad signaling via the cytoplasmic form of the promyelocytic leukemia (cPML) protein to contribute to EMT and invasion during the pathogenesis of NPM1c + AML [65].

Previous studies have also demonstrated that NPM1 can interact with hexamethylene bisacetamide-inducible protein 1 (HEXIM1), an inhibitor of positive transcription elongation factor $\mathrm{b}$ (P-TEFb) and a novel positive regulator of $\mathrm{p} 53$. In NPM1c + AML cells, NPM1c + sequesters HEXIM1 in the cytoplasm, resulting in a high level of RNA Pol II transcription (Fig. 4) [32]. By exploiting the interacting domain of the basic region (BR) of HEXIM1, which mediates the binding with NPM1 that is responsible for ubiquitination by the human double minute 2 protein to promote degradation, an innovative cytotoxic peptide fused with a cell-penetrating or breast 


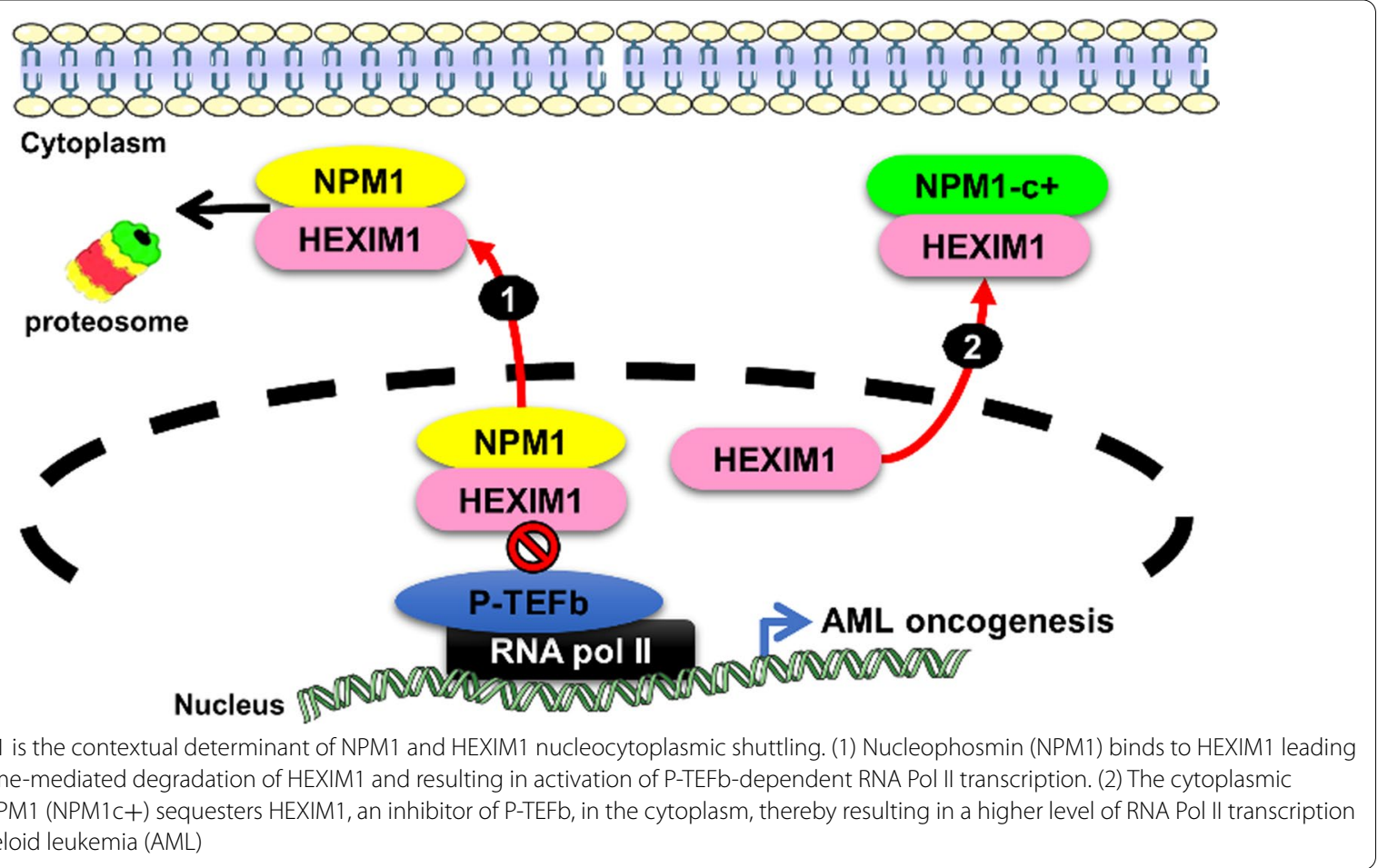

cancer-specific peptide-the HEXIM1 BR peptide-was developed and found to trigger rapid specific cytotoxic killing of breast cancer cells [31]. In summary, elucidating how NPM1 abnormalities and/or aberrant nucleocytoplasmic shuttling contributes to tumor progression is emerging as a need for developing innovative targeting strategies for the improvement of cancer therapy.

\section{Mortalin is the contextual determinant of p53 nucleocytoplasmic shuttling}

In normal cells, p53 is expressed in such a low quantity that it is undetectable by immunofluorescence and immunohistochemistry but is critical for modulating cell cycle progression, apoptosis, DNA repair and genomic stability as the guardian of the genome to maintain cell homeostasis [66]. In cancer or stressed cells, p53 is classified as a tumor suppressor and acts as a sensor of multiple forms of cellular stresses; it has been known for decades to have different subcellular localizations (in the nucleus and cytoplasm), but both the detailed mechanism responsible for its retention and its potential clinical application remain obscure $[67,68]$.

Mortalin is a $74 \mathrm{kDa}$ mitochondrial chaperone protein that is a member of the heat shock protein 70 (Hsp70) family [69]. Mortalin has been demonstrated to exhibit different subcellular distributions in normal and cancer cells and performs multiple functions in processes ranging from stress responses and intracellular trafficking to cell proliferation and tumorigenesis [70]. The molecular functions of mortalin are commonly determined by its interaction partners and subcellular localization [71]. Mortalin is the contextual determinant of cytoplasmic sequestration of $\mathrm{p} 53$, as demonstrated by coimmunoprecipitation experiments in colon cancer cells (in which it was localized in puncta) and by immunohistochemistry in colon cancer tissues [72]. Loss of the tumor-suppressive functions of nuclear p53 by its cytoplasmic sequestration is a general mechanism for p53 inactivation leading to loss of the capability to modulate centrosome duplication and genome stability in undifferentiated neuroblastoma and other cancers $[67,73,74]$. Indeed, mortalin overexpression has been identified as a biomarker of HCC metastasis and recurrence [75].

After molecular dissection of the mortalin-p53 interaction, mortalin was found to bind to the p53 C-terminal tetramerization (TET) domain (323 355 amino acids) in cancer cells but not in normal cells, and this observation was applied to develop inhibitors targeting cytoplasmically sequestered p53-mortalin and reactivate the tumorsuppressive activities of p53 via shuttling it back to the nucleus. At least three strategies to disrupt the cytoplasmic sequestrated mortalin-p53 interaction, including (a) a cytoplasmically localized p53 polypeptide containing the C-terminal residues 323-337 as a competitor of p53 in the p53-mortalin interaction [34], (b) a cationic rhodacyanine dye analog MKT-077 bound to mortalin [35], 
and (c) shRNA-mediated mortalin silencing [33], were shown to release p53 from mortalin-p53 complexes, to mediate the nuclear translocation and reactivation of tumor-suppressive p53, and to cause growth arrest and apoptosis in different human liver cancer cells (Fig. 5).

\section{EBP50 is a contextual determinant of EBP50 and $\beta$-catenin nucleocytoplasmic shuttling}

Dysregulation of the Wnt/ $\beta$-Catenin signaling pathway plays important roles in cancer stemness and tumor progression [77]. After activation with Wnt ligands, unphosphorylated and stabilized $\beta$-catenin enters the nucleus through nucleocytoplasmic shuttling and accumulates in the nucleus, where it forms a transcription complex with the transcription factor $\mathrm{T}$ cell factor (TCF) to transactivate downstream oncogenic gene expression [78].

ERM-binding phosphoprotein 50 (EBP50) (also called SLC9A3 regulator or NHERF1, $\mathrm{Na}+/ \mathrm{H}+$ exchanger regulatory factor 1), containing two tandem PDZ domains and a C-terminal ERM-binding (ezrinradixin-moesin-binding) domain, was reported to be an adaptor for protein interactions in multiple subcellular localizations with divergent functions [79]. EBP50 is a known $\beta$-catenin-associated protein and is overexpressed in the nucleus of HCC cells to stabilize and enhance the oncogenic transcriptional activity of $\beta$-catenin to promote tumor growth (Fig. 6) [80]. In contrast, EBP50 also acts as a tumor suppressor by recruiting PTEN to PDGFR at the plasma membrane to form the EBP50/PTEN/PDGFR ternary complex to suppress PI3K activation in normal cells [36]. Nuclear EBP50 was shown by chromatin immunoprecipitation assays to occupy consensus DNA sequences in Wntresponsive binding motifs, and it stabilizes $\beta$-catenin/ TCF-1 complexes or even $\beta$-catenin/dnTCF-1 complexes (dnTCF-1 is a truncation mutant of TCF-1 lacking the $\beta$-catenin-binding domain and acting as a transcriptional suppressor) to form a ternary molecular complex to enhance Wnt/ $\beta$-catenin signaling and downstream c-Myc and cyclin D1 oncogene expression. Moreover, the expression of nuclear EBP50 in human colorectal carcinoma cell lines was shown to enhance cell cycle progression, anchorage-independent growth, and tumorigenesis in a mouse model and was found to be associated with poor clinical outcome in patients with human primary colorectal tumors [37]. Knockdown of EBP50 with siRNA (siEBP50) disrupted the $\beta$-catenin and TCF-1 interaction to downregulate downstream c-Myc and cyclin D1 expression, suppress colon cancer cell proliferation and colony formation, and inhibit tumor growth in a NOD-SCID mouse model.

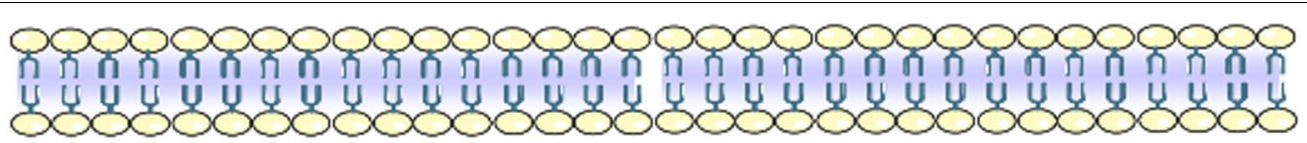

Cytoplasm

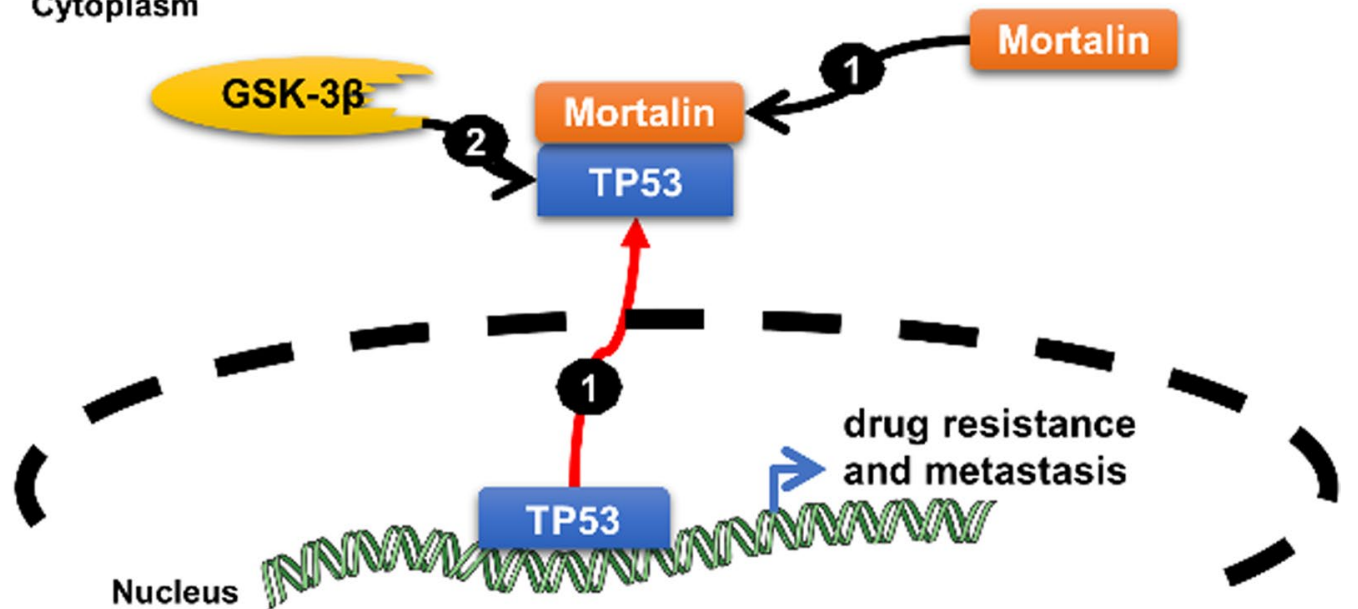

Fig. 5 Mortalin is the contextual determinant of p53 (TP53) nucleocytoplasmic shuttling. (1) Cytoplasmic p53 is sequestered by the heat shock protein mortalin in cancer cells through multiple mechanisms, including excess nuclear export of p53, defective cytoplasmic degradation, retention by cytoskeletal proteins and other potential mechanisms. (2) Glycogen synthase kinase-3 beta (GSK-3beta) phosphorylates p53 to induce its cytoplasmic localization, thereby enhancing constitutive cytoplasmic localization of p53 under ER stress to prevent p53 stabilization and p53-mediated apoptosis upon DNA damage [76] 

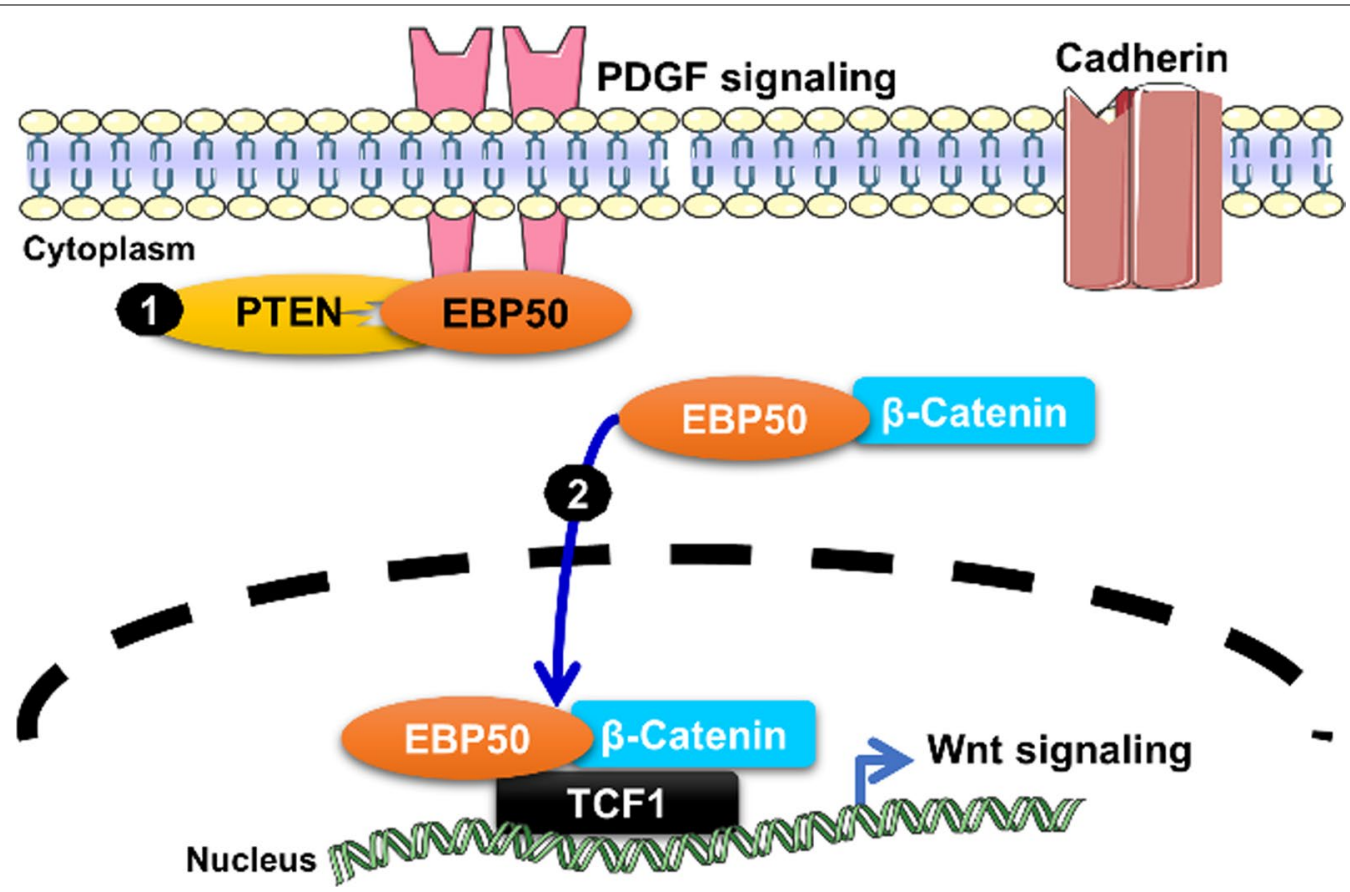

Fig. 6 EBP50 is a contextual determinant of EBP50 and $\beta$-catenin nucleocytoplasmic shuttling. (1) EBP50 interacts with the PTEN tumor suppressor to attenuate PDGF receptor signaling. (2) During tumor progression, EBP50 translocates to the nucleus to stabilize $\beta$-catenin/TCF-1 or dnTCF-1 for activation of Wnt oncogenic signaling

\section{Conclusions}

Aberrant nucleocytoplasmic shuttling is emerging as a hallmark in cancer progression owing to alterations in diverse mechanisms in the protein shuttling machinery that are commonly reported in multiple cancer types. Although emerging therapeutic agents targeting consensus determinants, such as SINE inhibitors targeting XPO1, have gained accelerated FDA approval and been evaluated as anticancer therapies in multiple phase I/ II clinical trials in the last 3 years, endeavors to better understand the molecular mechanisms and select other factors in nucleocytoplasmic shuttling for the development of innovative cancer therapies could be promising. Here, we suggest that PSPC1, TGIF1, NPM, Mortalin and EBP50 are contextual determinants that activate nucleocytoplasmic shuttling of tumor suppressors and oncogenes with opposite tumorigenic effects in different subcellular locations. Therefore, the critical nucleocytoplasmic shuttling determinants should be potential targets of developing therapeutic agents to inhibit aberrant determinants and shuttling proteins as an innovative anticancer approach leading to synergistic tumor suppression.

\section{Acknowledgements \\ None.}

Authors' contributions

Y.D.L. and Y.S.J. collected materials, prepared art works, edited, drafted and revised the manuscript. Both the authors read and approved the final manuscript.

\section{Funding}

Academia Sinica and Ministry of Science and Technology of Taiwan supported our work (MOST 107-0210-01-19-01, 108-2321-B-001-010, and 109-2320-B-001-014-MY3), CRC grants of IBMS (IBMS-CRC108-P02) and AS investigator award (AS-IA-109-L03) for Y.-S.J.

Availability of data and materials

Not applicable.

\section{Declarations}

Ethics approval and consent to participate Not applicable.

Consent for publication Not applicable.

\section{Competing interests}

The authors declare no conflicts of interest.

Received: 2 April 2021 Accepted: 24 July 2021

Published online: 02 August 2021 


\section{References}

1. Nigg EA. Nucleocytoplasmic transport: signals, mechanisms and regulation. Nature. 1997;386:779-87.

2. Görlich D. Transport into and out of the cell nucleus. Embo J. 1998;17:2721-7.

3. Xu L, Massagué J. Nucleocytoplasmic shuttling of signal transducers. Nat Rev Mol Cell Biol. 2004;5:209-19.

4. Fu X, Liang C, Li F, Wang L, Wu X, Lu A, et al. The rules and functions of nucleocytoplasmic shuttling proteins. Int J Mol Sci. 2018:19(5):1445.

5. Liang SH, Clarke MF. Regulation of p53 localization. Eur J Biochem. 2001;268:2779-83.

6. Sharpless NE, DePinho RA. p53: Good cop/bad cop. Cell. 2002;110:9-12.

7. Hung M-C, Link W. Protein localization in disease and therapy. J Cell Sci. 2011;124:3381-92.

8. Wang X, Li S. Protein mislocalization: mechanisms, functions and clinical applications in cancer. Biochim Biophys Acta. 2014;1846:13-25.

9. Turner JG, Dawson J, Sullivan DM. Nuclear export of proteins and drug resistance in cancer. Biochem Pharmacol. 2012;83:1021-32.

10. Conforti F, Wang Y, Rodriguez JA, Alberobello AT, Zhang YW, Giaccone G. Molecular pathways: anticancer activity by inhibition of nucleocytoplasmic shuttling. Clin Cancer Res. 2015;21:4508-13.

11. Fu SC, Huang HC, Horton P, Juan HF. ValidNESs: a database of validated leucine-rich nuclear export signals. Nucleic Acids Res. 2013;41:D338-43.

12. Benkova K, Mihalyova J, Hajek R, Jelinek T. Selinexor, selective inhibitor of nuclear export: unselective bullet for blood cancers. Blood Rev. 2021;46:100758.

13. Parikh K, Cang S, Sekhri A, Liu D. Selective inhibitors of nuclear export (SINE) — a novel class of anti-cancer agents. J Hematol Oncol. 2014;7:78.

14. Senapedis WT, Baloglu E, Landesman Y. Clinical translation of nuclear export inhibitors in cancer. Semin Cancer Biol. 2014;27:74-86.

15. Wang AY, Liu H. The past, present, and future of CRM1/XPO1 inhibitors. Stem Cell Investig. 2019;6:6.

16. Syed YY. Selinexor: First global approval. Drugs. 2019;79:1485-94.

17. Peterson TJ, Orozco J, Buege M. Selinexor. A first-in-class nuclear export inhibitor for management of multiply relapsed multiple myeloma. Ann Pharmacother. 2020;54:577-82.

18. Meyer T, Vinkemeier U. Nucleocytoplasmic shuttling of STAT transcription factors. Eur J Biochem. 2004:271:4606-12.

19. Tang J, Di J, Cao H, Bai J, Zheng J. p53-mediated autophagic regulation: a prospective strategy for cancer therapy. Cancer Lett. 2015;363:101-7.

20. Shyu AB, Wilkinson MF. The double lives of shuttling mRNA binding proteins. Cell. 2000;102:135-8.

21. Tecalco-Cruz AC. Molecular pathways involved in the transport of nuclear receptors from the nucleus to cytoplasm. J Steroid Biochem Mol Biol. 2018;178:36-44

22. Lo HW, Hsu SC, Hung MC. EGFR signaling pathway in breast cancers: from traditional signal transduction to direct nuclear translocalization. Breast Cancer Res Treat. 2006;95:211-8

23. Osborne MJ, Borden KL. The eukaryotic translation initiation factor elF4E in the nucleus: taking the road less traveled. Immunol Rev. 2015;263:210-23.

24. Lukong KE, Huot ME, Richard S. BRK phosphorylates PSF promoting its cytoplasmic localization and cell cycle arrest. Cell Signal. 2009;21:1415-22.

25. Henderson BR, Fagotto F. The ins and outs of APC and beta-catenin nuclear transport. EMBO Rep. 2002;3:834-9.

26. Yeh HW, Hsu EC, Lee SS, Lang YD, Lin YC, Chang CY, et al. PSPC1 mediates TGF- $\beta 1$ autocrine signalling and Smad2/3 target switching to promote EMT, stemness and metastasis. Nat Cell Biol. 2018;20:479-91.

27. Lang YD, Chen HY, Ho CM, Shih JH, Hsu EC, Shen R, et al. PSPC1-interchanged interactions with PTK6 and $\beta$-catenin synergize oncogenic subcellular translocations and tumor progression. Nat Commun. 2019;10:5716

28. Lang YD, Jou YS. PSPC1: a contextual determinant of tumor progression. Mol Cell Oncol. 2020;7:1721253.

29. Lin HK, Bergmann S, Pandolfi PP. Cytoplasmic PML function in TGF-beta signalling. Nature. 2004;431:205-11.

30. Buczek ME, Miles AK, Green W, Johnson C, Boocock DJ, Pockley AG, et al Cytoplasmic PML promotes TGF- $\beta$-associated epithelial-mesenchymal transition and invasion in prostate cancer. Oncogene. 2016;35:3465-75.
31. Neo SH, Lew QJ, Koh SM, Zheng L, Bi X, Chao SH. Use of a novel cytotoxic HEXIM1 peptide in the directed breast cancer therapy. Oncotarget. 2016:7:5483-94.

32. Gurumurthy M, Tan CH, Ng R, Zeiger L, Lau J, Lee J, et al. Nucleophosmin interacts with HEXIM1 and regulates RNA polymerase II transcription. J Mol Biol. 2008;378:302-17.

33. Lu WJ, Lee NP, Kaul SC, Lan F, Poon RT, Wadhwa R, et al. Induction of mutant p53-dependent apoptosis in human hepatocellular carcinoma by targeting stress protein mortalin. Int J Cancer. 2011;129:1806-14.

34. Kaul SC, Aida S, Yaguchi T, Kaur K, Wadhwa R. Activation of wild type p53 function by its mortalin-binding, cytoplasmically localizing carboxyl terminus peptides. J Biol Chem. 2005;280:39373-9.

35. Wadhwa R, Sugihara T, Yoshida A, Nomura H, Reddel RR, Simpson R, et al. Selective toxicity of MKT-077 to cancer cells is mediated by its binding to the hsp70 family protein mot-2 and reactivation of p53 function. Cancer Res. 2000;60:6818-21.

36. Takahashi Y, Morales FC, Kreimann EL, Georgescu MM. PTEN tumor suppressor associates with NHERF proteins to attenuate PDGF receptor signaling. Embo J. 2006;25:910-20.

37. Lin YY, Hsu YH, Huang HY, Shann YJ, Huang CY, Wei SC, et al. Aberrant nuclear localization of EBP50 promotes colorectal carcinogenesis in xenotransplanted mice by modulating TCF-1 and $\beta$-catenin interactions. J Clin Invest. 2012;122:1881-94.

38. Fox AH, Lam YW, Leung AK, Lyon CE, Andersen J, Mann M, et al. Paraspeckles: a novel nuclear domain. Curr Biol. 2002;12:13-25.

39. Kuwahara S, Ikei A, Taguchi Y, Tabuchi Y, Fujimoto N, Obinata M, et al. PSPC1, NONO, and SFPQ are expressed in mouse Sertoli cells and may function as coregulators of androgen receptor-mediated transcription. Biol Reprod. 2006;75:352-9.

40. Gao X, Kong L, Lu X, Zhang G, Chi L, Jiang Y, et al. Paraspeckle protein 1 (PSPC1) is involved in the cisplatin induced DNA damage response-role in G1/S checkpoint. PLoS One. 2014;9:e97174.

41. Guallar D, Bi X, Pardavila JA, Huang X, Saenz C, Shi X, et al. RNA-dependent chromatin targeting of TET2 for endogenous retrovirus control in pluripotent stem cells. Nat Genet. 2018;50:443-51.

42. Wang J, Rajbhandari P, Damianov A, Han A, Sallam T, Waki H, et al. RNAbinding protein PSPC1 promotes the differentiation-dependent nuclear export of adipocyte RNAs. J Clin Invest. 2017;127:987-1004.

43. Jen HW, Gu DL, Lang YD, Jou YS. PSPC1 Potentiates IGF1R expression to augment cell adhesion and motility. Cells. 2020;9(6):1490.

44. Yeh HW, Lee SS, Chang CY, Lang YD, Jou YS. A new switch for TGF $\beta$ in cancer. Cancer Res. 2019:79:3797-805.

45. Mitchell PJ, Barker KT, Martindale JE, Kamalati T, Lowe PN, Page MJ, et al. Cloning and characterisation of cDNAs encoding a novel non-receptor tyrosine kinase, brk, expressed in human breast tumours. Oncogene. 1994;9:2383-90.

46. Derry JJ, Prins GS, Ray V, Tyner AL. Altered localization and activity of the intracellular tyrosine kinase BRK/Sik in prostate tumor cells. Oncogene. 2003:22:4212-20.

47. Goel RK, Lukong KE. Tracing the footprints of the breast cancer oncogene BRK_-past till present. Biochim Biophys Acta. 2015;1856:39-54.

48. Chen HY, Shen CH, Tsai YT, Lin FC, Huang YP, Chen RH. Brk activates rac1 and promotes cell migration and invasion by phosphorylating paxillin. Mol Cell Biol. 2004;24:10558-72.

49. Wotton D, Lo RS, Lee S, Massagué J. A smad transcriptional corepressor. Cell. 1999;97:29-39.

50. Seo SR, Lallemand F, Ferrand N, Pessah M, L'Hoste S, Camonis J, et al. The novel E3 ubiquitin ligase Tiul1 associates with TGIF to target Smad2 for degradation. Embo J. 2004;23:3780-92.

51. Seo SR, Ferrand N, Faresse N, Prunier C, Abécassis L, Pessah M, et al. Nuclear retention of the tumor suppressor CPML by the homeodomain protein TGIF restricts TGF-beta signaling. Mol Cell. 2006;23:547-59.

52. Goddard AD, Borrow J, Freemont PS, Solomon E. Characterization of a zinc finger gene disrupted by the $t(15 ; 17)$ in acute promyelocytic leukemia. Science. 1991;254:1371-4.

53. Kakizuka A, Miller WH Jr, Umesono K, Warrell RP Jr, Frankel SR, Murty WV, et al. Chromosomal translocation $\mathrm{t}(15 ; 17)$ in human acute promyelocytic leukemia fuses RAR alpha with a novel putative transcription factor. PML Cell. 1991;66:663-74

54. Pandolfi PP, Grignani F, Alcalay M, Mencarelli A, Biondi A, LoCoco F, et al. Structure and origin of the acute promyelocytic leukemia myl/RAR alpha 
CDNA and characterization of its retinoid-binding and transactivation properties. Oncogene. 1991;6:1285-92.

55. de Thé H, Lavau C, Marchio A, Chomienne C, Degos L, Dejean A. The PML-RAR alpha fusion mRNA generated by the $t(15 ; 17)$ translocation in acute promyelocytic leukemia encodes a functionally altered RAR. Cell. 1991;66:675-84.

56. Salomoni P, Pandolfi PP. The role of PML in tumor suppression. Cell. 2002;108:165-70.

57. Muindi JR, Frankel SR, Huselton C, DeGrazia F, Garland WA, Young CW, et al. Clinical pharmacology of oral all-trans retinoic acid in patients with acute promyelocytic leukemia. Cancer Res. 1992;52:2138-42.

58. Thomas X. Acute promyelocytic leukemia: a history over 60 years-from the most malignant to the most curable form of acute leukemia. Oncol Ther. 2019;7:33-65.

59. Luo F, Zhuang Y, Sides MD, Sanchez CG, Shan B, White ES, et al. Arsenic trioxide inhibits transforming growth factor- $\beta 1$-induced fibroblast to myofibroblast differentiation in vitro and bleomycin induced lung fibrosis in vivo. Respir Res. 2014;15:51.

60. Lindström MS. NPM1/B23: a multifunctional chaperone in ribosome biogenesis and chromatin remodeling. Biochem Res Int. 2011:2011:195209.

61. Kurki S, Peltonen K, Latonen L, Kiviharju TM, Ojala PM, Meek D, et al. Nucleolar protein NPM interacts with HDM2 and protects tumor suppressor protein p53 from HDM2-mediated degradation. Cancer Cell. 2004;5:465-75.

62. Li Z, Hann SR. Nucleophosmin is essential for c-Myc nucleolar localization and c-Myc-mediated rDNA transcription. Oncogene. 2013;32:1988-94.

63. Karimi Dermani F, Gholamzadeh Khoei S, Afshar S, Amini R. The potential role of nucleophosmin (NPM1) in the development of cancer. J Cell Physiol. 2021. https://doi.org/10.1002/jcp.30406.

64. Falini B, Martelli MP, Bolli N, Sportoletti P, Liso A, Tiacci E, et al. Acute myeloid leukemia with mutated nucleophosmin (NPM1): is it a distinct entity? Blood. 2011;117:1109-20.

65. Yang L, Wang L, Yang Z, Jin H, Zou Q, Zhan Q, et al. Up-regulation of EMT-related gene VCAN by NPM1 mutant-driven TGF- $\beta / C P M L$ signalling promotes leukemia cell invasion. J Cancer. 2019;10:6570-83.

66. Barnoud T, Indeglia A, Murphy ME. Shifting the paradigms for tumor suppression: lessons from the p53 field. Oncogene. 2021;40:4281-90.

67. Moll UM, LaQuaglia M, Bénard J, Riou G. Wild-type p53 protein undergoes cytoplasmic sequestration in undifferentiated neuroblastomas but not in differentiated tumors. Proc Natl Acad Sci U S A. 1995;92:4407-11.

68. O'Keefe K, Li H, Zhang Y. Nucleocytoplasmic shuttling of p53 is essential for MDM2-mediated cytoplasmic degradation but not ubiquitination. Mol Cell Biol. 2003;23:6396-405.
69. Deocaris CC, Kaul SC, Wadhwa R. On the brotherhood of the mitochondrial chaperones mortalin and heat shock protein 60. Cell Stress Chaperones. 2006:11:116-28.

70. Wadhwa R, Taira K, Kaul SC. An Hsp70 family chaperone, mortalin/ mthsp70/PBP74/Grp75: what, when, and where? Cell Stress Chaperones. 2002;7:309-16.

71. Londono C, Osorio C, Gama V, Alzate O. Mortalin, apoptosis, and neurodegeneration. Biomolecules. 2012;2:143-64.

72. Gestl EE, Anne Böttger S. Cytoplasmic sequestration of the tumor suppressor p53 by a heat shock protein 70 family member, mortalin, in human colorectal adenocarcinoma cell lines. Biochem Biophys Res Commun. 2012;423:411-6.

73. Wadhwa R, Takano S, Robert M, Yoshida A, Nomura H, Reddel RR, et al. Inactivation of tumor suppressor p53 by mot-2, a hsp70 family member. J Biol Chem. 1998;273:29586-91.

74. Ma Z, Izumi H, Kanai M, Kabuyama Y, Ahn NG, Fukasawa K. Mortalin controls centrosome duplication via modulating centrosomal localization of p53. Oncogene. 2006;25:5377-90.

75. Yi X, Luk JM, Lee NP, Peng J, Leng X, Guan XY, et al. Association of mortalin (HSPA9) with liver cancer metastasis and prediction for early tumor recurrence. Mol Cell Proteomics. 2008;7:315-25.

76. Qu L, Huang S, Baltzis D, Rivas-Estilla AM, Pluquet O, Hatzoglou M, et al. Endoplasmic reticulum stress induces p53 cytoplasmic localization and prevents p53-dependent apoptosis by a pathway involving glycogen synthase kinase-3beta. Genes Dev. 2004;18:261-77.

77. Klaus A, Birchmeier W. Wnt signalling and its impact on development and cancer. Nat Rev Cancer. 2008;8:387-98

78. Russell JO, Monga SP. Wnt/ $\beta$-catenin signaling in liver development, homeostasis, and pathobiology. Annu Rev Pathol. 2018;13:351-78.

79. Shenolikar S, Voltz JW, Cunningham R, Weinman EJ. Regulation of ion transport by the NHERF family of PDZ proteins. Physiology (Bethesda). 2004;19:362-9.

80. Shibata T, Chuma M, Kokubu A, Sakamoto M, Hirohashi S. EBP50, a beta-catenin-associating protein, enhances Wnt signaling and is overexpressed in hepatocellular carcinoma. Hepatology. 2003;38:178-86.

\section{Publisher's Note}

Springer Nature remains neutral with regard to jurisdictional claims in published maps and institutional affiliations.
Ready to submit your research? Choose BMC and benefit from:

- fast, convenient online submission

- thorough peer review by experienced researchers in your field

- rapid publication on acceptance

- support for research data, including large and complex data types

- gold Open Access which fosters wider collaboration and increased citations

- maximum visibility for your research: over $100 \mathrm{M}$ website views per year

At BMC, research is always in progress.

Learn more biomedcentral.com/submissions 